\title{
Mitigation of Phase Noise and Nonlinearities for High Capacity Radio-over-Fiber Links
}

\author{
Muhammad Kamal Asif Khan ${ }^{1}$, Farman Ali ${ }^{2, *}$, Muhammad Irfan ${ }^{3, *} \mathbb{\oplus}$, Fazal Muhammad $4, * \mathbb{C}$, Faisal Althobiani ${ }^{5}$, \\ Asar Ali ${ }^{6}$, Suliman Khan ${ }^{7}$ (i), Saifur Rahman ${ }^{3}\left(\mathbb{D}\right.$, Grzegorz Perun ${ }^{8}$ and Adam Glowacz ${ }^{9, *}$ (D)
}

1 Mechanical Engineering Department, College of Engineering, Najran University, Najran 61441, Saudi Arabia; mkkhan@nu.edu.sa

2 Department of Electrical Engineering, Qurtuba University of Science and Information Technology, Dera Ismail Khan, Khyber Pakhtunkhwa 29050, Pakistan

3 Electrical Engineering Department, College of Engineering, Najran University, Najran 61441, Saudia Arabia; srrahman@nu.edu.sa

4 Department of Electrical Engineering, University of Engineering Technology, Mardan 23200, Pakistan

5 Faculty of Maritime Studies, King Abdulaziz University, P.O. Box 80401, Jeddah 21589, Saudi Arabia; falthobiani@kau.edu.sa

6 Department of Electrical Engineering, Wah Engineering College, University of Wah, Wah Cantt 47040, Pakistan; asar.ali@wecuw.edu.pk

7 Key Lab of Power Electronics for Energy Conservation and Motor Drive of Hebei Province, Yanshan University, Qinhuangdao 066004, China; engr_suliman_131@stumail.ysu.edu.cn

8 Faculty of Transport and Aviation Engineering, Silesian University of Technology, 40-019 Katowice, Poland; grzegorz.perun@polsl.pl

9 Department of Automatic Control and Robotics, Faculty of Electrical Engineering, Automatics, Computer Science and Biomedical Engineering, AGH University of Science and Technology, al. A. Mickiewicza 30, 30-059 Kraków, Poland

Citation: Asif Khan, M.K.; Ali, F; Irfan, M.; Muhammad, F.; Althobiani, F.; Ali, A.; Khan, S.; Rahman, S.; Perun, G.; Glowacz, A. Mitigation of Phase Noise and Nonlinearities for High Capacity Radio-over-Fiber Links. Electronics 2021, 10, 345. https://doi.org/ 10.3390/electronics10030345

Academic Editors: Dongkyun Kim and Muhammad Azfar Yaqub Received: 3 December 2020 Accepted: 27 January 2021 Published: 1 February 2021

Publisher's Note: MDPI stays neutral with regard to jurisdictional clai$\mathrm{ms}$ in published maps and institutional affiliations.

Copyright: $\odot 2021$ by the authors. Licensee MDPI, Basel, Switzerland. This article is an open access article distributed under the terms and conditions of the Creative Commons Attribution (CC BY) license (https:// creativecommons.org/licenses/by/ $4.0 /)$.
* Correspondence: drfarmanali.optics@qurtuba.edu.pk (F.A.); miditta@nu.edu.sa (M.I.); fazal.muhammad@uetmardan.edu.pk (F.M.); adglow@agh.edu.pl (A.G.)

Abstract: Radio-over-fiber (RoF) links successfully provide high data rates and bandwidth capacity with a low complexity system architecture, as compared to its counterpart digital-RoF. In addition, the compound of quadrature amplitude modulation (QAM) and orthogonal frequency division multiplexed (OFDM) modulation schemes further enhance the process of these achievements. However, high data rates and bandwidth-capacity-supported RoF links face nonlinearities (NLs), linear distortions (LDs), and phase noise challenges that degrade the reliability of communication networks (CNs). Therefore, in this paper, to suppress NLs, LDs, and phase noise, next generation cloud radio access networks (CRANs) are investigated using RoF links and wavelength division multiplexing (WDM) methodology based on 16, 32, and 64 QAM-OFDM modulation schemes. The receiver of the proposed framework is designed, applying an improved digital signal processing (DSP) system that includes overlap frequency domain equalization (OFDE), a synchronization process, and time domain equalization (TDE). Theoretical and simulation models are organized for estimating the proposed RoF link with the aid of different values of transmission ranges, input power, output power, bit rate, bits per symbol, channel spacing, and the number of users. The fitness of the model matches that of existing approaches.

Keywords: 16, 32, and 64 QAM-OFDM; radio over fiber links; nonlinearities (NLs); linear distortions (LDs)

\section{Introduction}

Utilizing optical fiber transmission networks (OFTNs) with a long transmission span that transport multi-Gb/s of data introduces nonlinearities (NLs) and linear distortions (LDs) [1,2]. The NLs are divided into two types, the refractive-index-related NLs and scattered NLs. The system capacity and efficiency are degraded due to refractive-index-related 
NLs that include four wave mixing (FWM), cross phase modulation (XPM), and self-phase modulation (SPM). Similarly, LDs consist of chromatic dispersion (CD), polarization mode dispersion (OMD), and attenuation, which causes the destruction of received optical fibers and decreases transmission quality [3,4]. The phase noise is introduced in view of the non-zero linewidth of the laser and the transformation of the intensity noise of optical amplifiers into phase modulation after passing through a dispersive optical fiber over long distances. As optical fiber transmission systems are considered the backbone of modern communication systems, with no alternate solution to replace them, there is a crucial demand for a new approach to address the issues related to optical fiber transmission [5]. Currently, the integration of radio signals and OFTNs are considered a significant part of fifth generation (5G) cellular networks for a high-capacity and cost-effective approach towards a stand-alone system architecture [6]. The integration of radio frequency (RF) and OFTNs is termed in many ways depending on the system design, such as microwave photonic links (MPL), a microwave transmission over fiber (MTF), or a radio over fiber (RoF) $[7,8]$. The transmission cost is minimized because it avoids analogue-to-digital (ADC) and digital-to-analogue (DAC) transformations, so high-capacity wireless transmission can be provided by RoF links with low power consumption [9]. In order to meet the rapidly increasing demand for broadband multimedia services, RoF technology is a suitable solution for wireless signal distribution over optical fibers. However, the analogue RoF techniques have drawbacks, such as the susceptibility of microwave optical components to NLs, the degradation of the dynamic range over optical links, and the requirement of expensive high-frequency components. Thanks to matured digital technologies, a digitized RoF is free from the issues of analog systems. Moreover, it simplifies the architecture of base-station wireless optical backhaul networks, which enable easy integration with existing and future broadband optical and high-speed networks, as the transmission is in a digital form over fibers. Besides, the adaptation of mobile communication for different standards and flexibility is organized by RoF systems associated with the evolution of the forthcoming $5 \mathrm{G}$ mobile communication [10]. The performance of RoF links can be further modified using wavelength division multiplexing (WDM) technology, which transmit multiple signals over a single fiber with different wavelengths [11,12]. However, the propagation of pulses in this manner are distorted when they interface with each other. These generated distortions consist of NLs, LDs, and phase noise. With the intention of compensating the NLs, LDs, and phase noise, advance modulation schemes are installed, and these aim to make input light pulse spectrally efficient and to be able to carry high-capacity information for long spans. In this paper, improved quadrature amplitude modulation (QAM) with the integral of orthogonal frequency division multiplexing (OFDM) is examined for transmitting multiple signals over WDM-based RoF links validly in spite of the impact of NLs, LDs, and phase noise. The process of reshaping the quality of received multiple signals are further improved with the aid of upgraded overlap frequency domain equalization (OFDE) synchronization and time domain equalization (TDE) scenarios.

\subsection{Related Work}

Studies have shown that advance-modulation-based RoF communication networks and upgraded digital signal processing (DSP) receivers are robust solutions to mitigate NLs, LDs, and phase noise and increase reliable connectivity. In [13], the authors reviewed the RoF technique for a next generation optical network using multi-core fibers. The delivery of energy was described to show the limits on power in terms of attenuation, linewidth, and effective area. A spectrally efficient coherent RoF system was proposed in [14] using linear digital phase demodulation. The scheme was verified for a $25 \mathrm{~km}$ transmission range, 16 QAM, and multiple users. In [15], the authors analyzed a wireless local area network using an OFDM-RoF-based system and a microstrip antenna. A mm-wave RoF outdoor system employing a free space RF channel working at a $25 \mathrm{GHz}$ band was studied in [16]. A directly modulated laser, an electro absorption modulator, and a mach zehnder modulator (MZM) were implemented by the authors. In [17], the authors discussed a 
remote radio fronted through silicon photonics for an mm-wave RoF system. Moreover, a procedure combining an MZM and a micro ring modulator was utilized to create $40 \mathrm{GHz}$ single sideband signals. A full duplex analog RoF link was demonstrated in [18] with an ultra integrated III v-on-silicon transceiver. A C-band and O-band were realized for downstream and upstream links, respectively. In [19], the authors explored an mm-wave RoF system and free space wireless transmission using a distributed feedback laser. A rate of $6 \mathrm{Gbps}$ with a 64 QAM was successfully transmitted up to a $50 \mathrm{~km}$ transmission span. The combined approach of RoF and free space optics was investigated in [20] with a 24-26 GHz frequency band. In [21], the authors proposed a RoF fonthaul with intensity modulation for downlink phase modulation for uplinks. However, the demands of a long range transmission, a high capacity, and a reliable architecture are increasing exponentially, which has made NLs, LDs, and phase noise increasingly relevant. Thus, for efficient next generation mobile networks, a WDM-RoF link is presented in this paper, aiming to handle the factors of NLs, LDs, and phase noise.

\subsection{Major Contributions}

Previous studies reveal that managing users' high capacity demands increases the burden on current RoF transmission links. As a result, communication network (CN) functionality is strongly affected due to the generation of NLs, LDs, and phase noise. Therefore, this paper proposes a modern $\mathrm{CN}$ based on a WDM-RoF system that is designed to compensate for the NLs, LDs, and phase noise and to optimize the structure of access networks (ANs). The major contributions of the proposed scheme are listed below.

1. Physical optical transmission at long-range distances is considered in this work. Propagation channels include high order NLs, LDs, and conversion of intensity noise to phase noise.

2. Important parameters such as input power, output power, channel spacing, the number of channels, bandwidth capacity, and fiber span are applied to compute the findings of the proposed research work.

3. Advanced modulation schemes such as 16, 32, and 64 QAM-OFDM are employed to upgrade the transmission capacity and data rate.

4. The joint setup of OFDE, a synchronization block, and TDE are used to degrade the NLs, LDs, and phase noise.

5. The performance of the WDM-RoF link is computed analytically, and the simulation analysis is estimated, suggesting a $20 \mathrm{~km}$ transmission path, a $-40 \mathrm{dBm}$ to $-15 \mathrm{dBm}$ received power, a $57 \mathrm{GHz}$ to $61 \mathrm{GHz}$ bandwidth capacity, $12.5 \mathrm{GHz}$ to $50 \mathrm{GHz}$ channel spacing, and $-20 \mathrm{dBm}$ to $0 \mathrm{dBm}$ input power.

The rest of the paper is organized as follows: The proposed model layout is explained in Section 2. Sections 3 and 4 summarize the analytical modeling results and discussion, respectively. Similarly, Section 5 explains the conclusion of the presented work.

\section{Proposed Model Layout}

This section highlights the enhanced 16, 32, and 64 QAM-OFDM-based WDM-RoF architecture including an improved DSP receiver mechanism for supporting NLs, LDs, and phase noise. The proposed model is presented in Figure 1, which consists of a transmitter, an optical medium, and a receiver with an advanced DSP system. Figure 1 shows that RF signals are transformed over advance modulation in 16, 32, and 64 QAM-OFDM formats. These received signals from QAM-OFDM are then amplified from the noises contained in the electrical domain using an electrical amplifier (EA). After amplification of the electrical signals, the data modulation is performed over an optical carrier using an MZM. A number of optical signals are multiplexed with the help of a WDM-multiplexer (WDM-MUX), where a single mode fiber (SMF) and an erbium-doped fiber amplifier (EDFA) are employed for propagating and modifying the laser waves, respectively. The WDM-deMUX is applied at the receiver on the ' $\mathrm{Kx}^{\prime}$ ' side of the SMF by using Fiber Bragg Grating (FBG), where a PIN photodiode is installed at the output of the WDM-deMUX, performing the optical to 
electrical (O/E) procedure. To compensate amplified spontaneous emission (ASE), and LDs low pass filter (LPF) and EA are implemented before generating M-ary pulses for QAM sequence decoder. To compensate the effects of the NLs, LDs, and phase noise, digital signal processing (DSP) techniques such as OFDM with OFDE, synchronization, and TDE are used. Such mechanisms improve the quality of the WDM-RoF link by minimizing the calculation complexity owing to its back-to-back operation. Moreover, the proposed DSP framework contains a smaller PAPR, which is more robust against NLs, LDs, and phase noise. As a result, the RF signals are received at the $\mathrm{Rx}$, where it can be transmitted to base stations (BSs). As the OFDM signals are pass-band-based signals, to obtain radio over fiber waves, a local oscillator is installed inside the OFDM block, whose purpose is to convert a data signal into intermediate frequencies.

To improve transmission quality and reduce NLs and phase noise, FDE-based optical transmission was introduced in [19]. This system is robust against phase noise with a basic FDE, but it fails to address the NLs in a long-haul optical RoF system. Therefore, an overlap FDE (OFDE) methodology is proposed in this work. The internal block of OFDE and TDE are explained in Figure 2. The attained signals at the receiver side are demodulated by OFDE and TDE. OFDE compensates for the NLs, LDs, and phase noise, and TDE then operates following the timing and frequency synchronization. Furthermore, TDE measures the received weight, applying a constant modulus and blind algorithms and data signals. The tape size of OFDE is larger than TDE, so the impairments are reduced significantly. The TDE is followed by a carrier phase estimation technique conducting carrier recovery. The schematic procedure of OFDE is shown in the inset of Figure 3, clarifying that a number of FDEs have a direct relation with the quantity of overlapping samples (Ns).

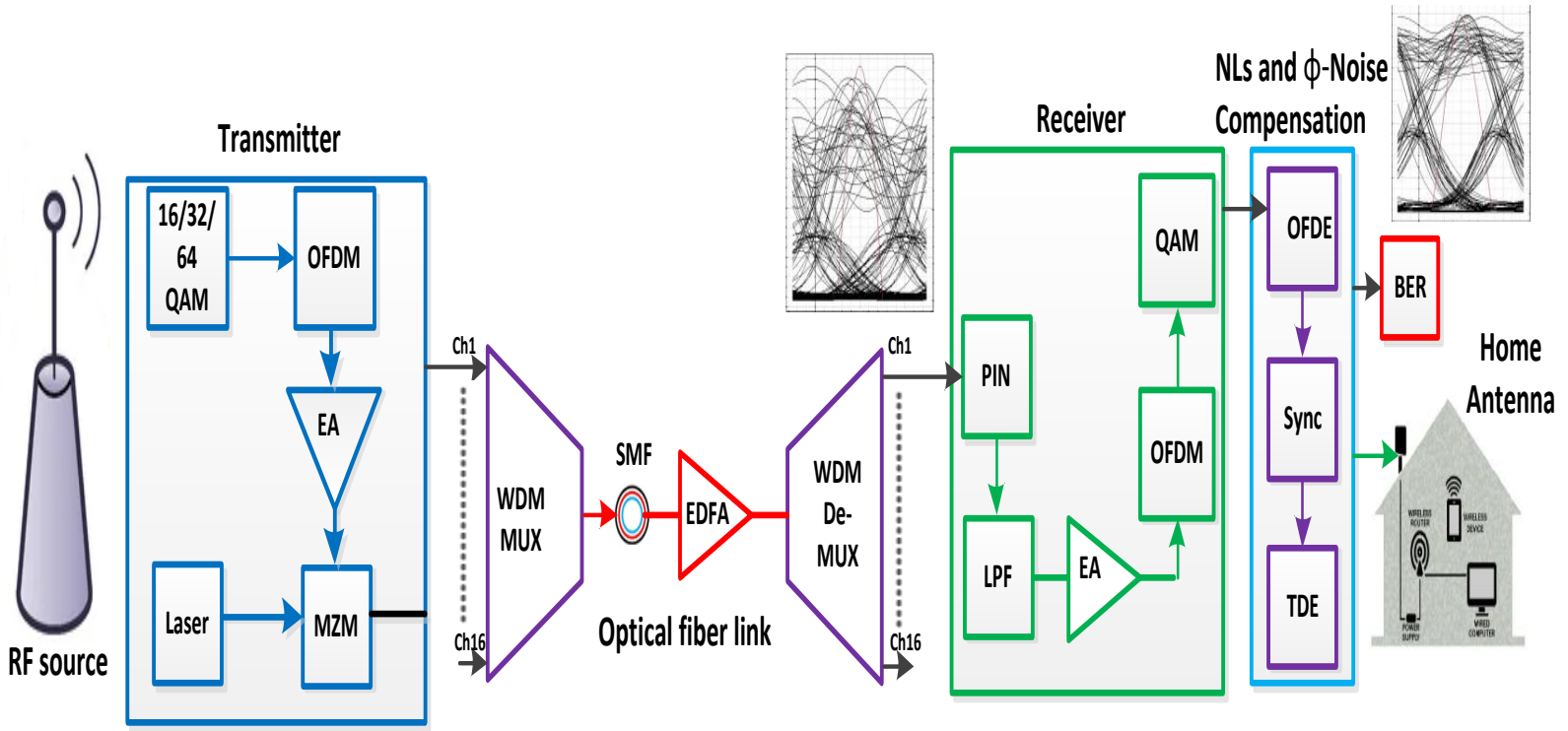

Figure 1. The proposed wavelength division multiplexing (WDM)-based Radio-over-fiber (RoF) model with an advanced digital signal processing (DSP) receiver.

The transmission quality is increased in OFDE than in FDE, and the structure is simplified. These received signals are then multiplied by FDE blocks in the frequency domain with a fixed calculated weight. The first and last Nc samples from the $\mathrm{N}$ samples are omitted after inverse FFT (IFFT) N points. The remaining Nr samples are extracted, and compensated NL, LD, and phase noise signals are achieved regularly by performing FDE in an overlapped FFT block.

A BER analyzer is employed for measuring and analyzing the quality of attained signals in spite of NLs, LDs, and phase noise. The BER takes outputs from a 3R-re generator, 
which creates re-amplified, re-shaped, and re-timed signals to further increase accuracy. A list of elements for investigating the simulation analysis of the proposed research work is shown in Table 1.

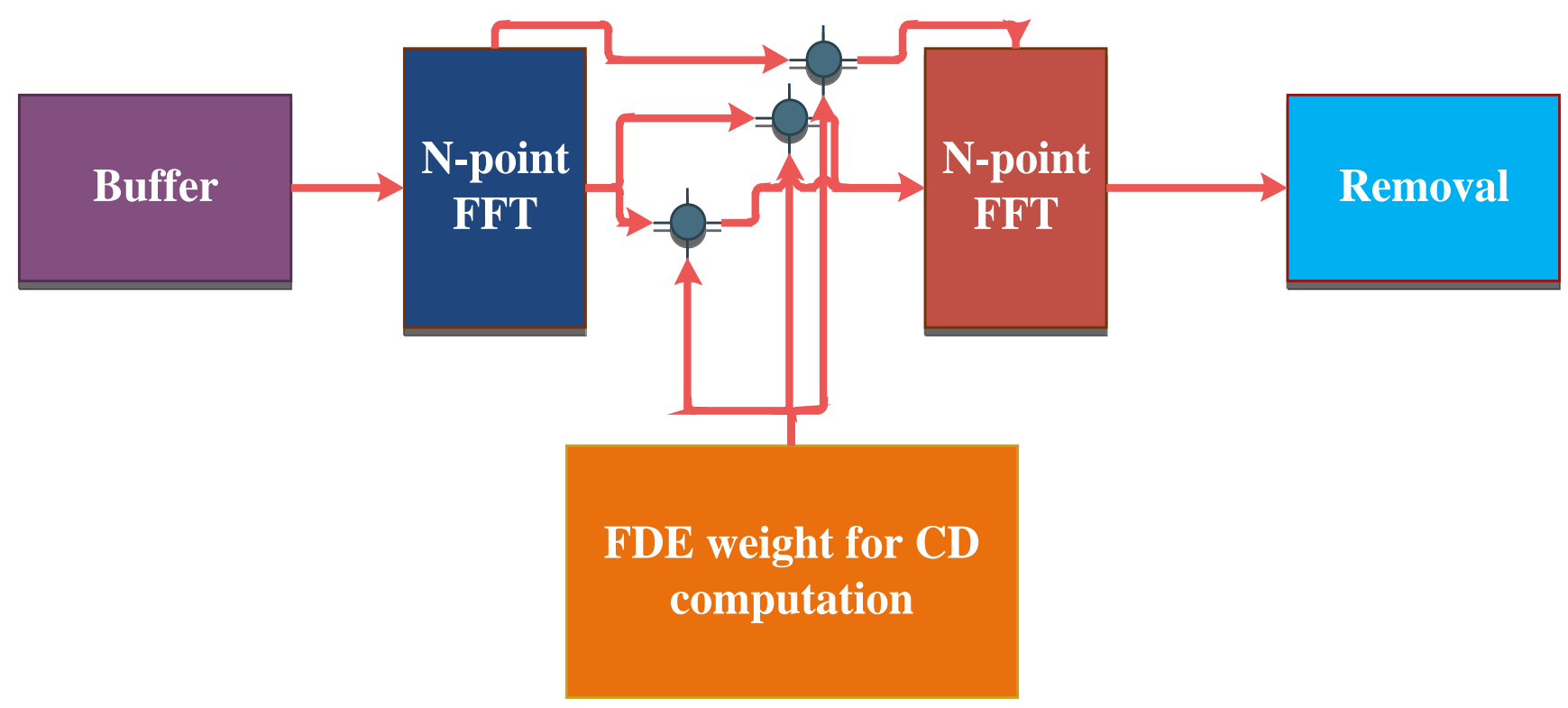

Figure 2. The proposed overlap frequency domain equalization (OFDE) structure.

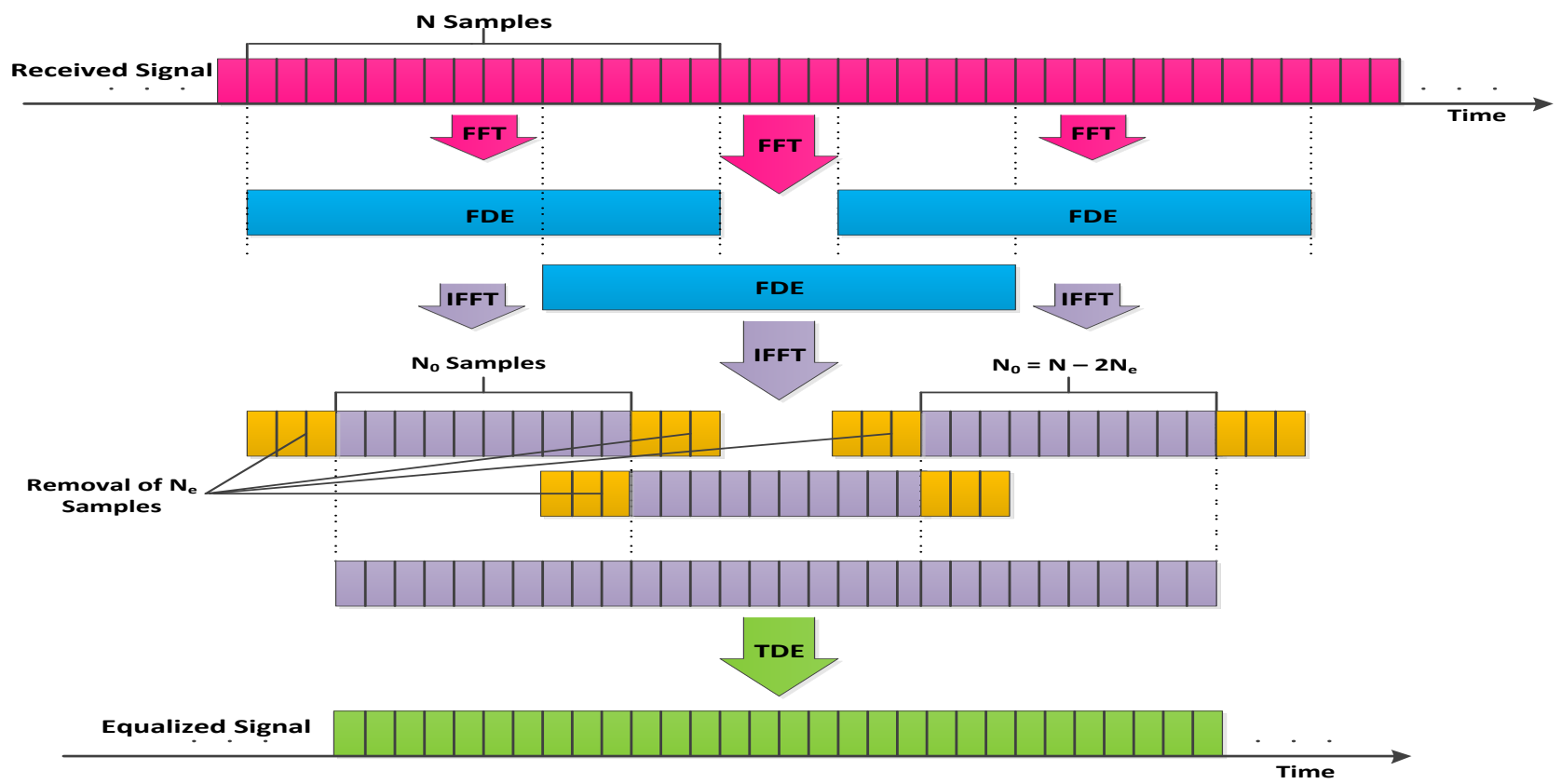

Figure 3. The proposed OFDE structure. 
Table 1. Description of parameters used for simulation analysis.

\begin{tabular}{ll}
\hline Description & Magnitude \\
\hline Data rate & $100 \mathrm{Gbps}$ \\
Bits per symbol & $6 \mathrm{bits}$ \\
Number of FFT points & 128 \\
Number of sub-carriers & 24 \\
Frequency & $3-7 \mathrm{GHz}$ \\
Gain & $10 \mathrm{~dB}$ \\
Noise power & $-34 \mathrm{dBm}$ \\
laser frequency of first channel & $193.1 \mathrm{THz}$ \\
Input power & $-20 \mathrm{dBm}$ to $0 \mathrm{dBm}$ \\
Attained power & $-40 \mathrm{dBm}$ to $-15 \mathrm{dBm}$ \\
Extinction ratio & $10 \mathrm{~dB}$ \\
Line width & $10 \mathrm{MHz}$ \\
Slope efficiency & $0.4 \mathrm{~W} / \mathrm{A}$ \\
Length & $10 \mathrm{~km}$ \\
Reference wavelength & $1553 \mathrm{~nm}$ \\
Dispersion & $16.75 \mathrm{ps} / \mathrm{nm} / \mathrm{km}$ \\
Dispersion slope & $0.075 \mathrm{ps} / \mathrm{nm}{ }^{2} / \mathrm{K}$ \\
Effective area & $80 \mu \mathrm{m}^{2}$ \\
Nonlinear refractive index & $2.6 \times 10^{-21}$ \\
\hline
\end{tabular}

\section{Analytical Modeling}

The proposed model is described in Section 2, while this section elaborates the theoretical proofs of the presented work. The transmitter ' $T x^{\prime}$ ' of the OFTN receives the RF signals from base stations (BSs), [22] which are estimated as

$$
\xi_{r}=\log (\kappa) / \log (2)
$$

The parameter $\xi_{r}$ denotes the RF received signals, and $\kappa$ describes the achieved signal length. A QAM block is used to attain the RF signals and divides it into two cascaded sequences, where each sequence is then transmitted with varying amplitudes ' $\sigma$ ' $[23,24]$ and computed as

$$
\sigma=\left(2_{n}-1-N\right), n=1,2,3, \ldots N .
$$

where $N=2^{i / 2}$ shows the number of possible sequences. The parameter $i$ is the number of bits per symbol. The square of $N$ explains the range of the QAM. In other words, $i=2$ and $M=2$ define 4 QAM, $i=4$ and $M=4$ define $16 \mathrm{QAM}, i=6$ and $M=8$ define 64 QAM, and $i=8$ and $M=16$ define 256 QAM. In this research model, $i=4$ and $M=4$ along with $i=6$ and $M=8$ are analyzed [25]. The string of bits coming from the QAM are split into two cascaded arrays. The output of QAM [26-29] is described as

$$
\begin{aligned}
M_{\text {out }}(\iota)= & C\left[J(t) \cos \left(2 \pi f_{a} \iota+\omega_{a}\right)-\right. \\
& \left.Q(\iota) \sin \left(2 \pi f_{a} \iota+\omega_{a}\right)\right]+\alpha
\end{aligned}
$$

Here, the real portion of the input signal is denoted by $J, Q$ is used for the imaginary part, $C$ is the gain, $f_{a}$ is the carrier frequency, and $\omega_{a}$ is the phase of the signal. The PAPR is another key element for measuring the performance of the transmitted signal, which 
is evaluated from the QAM sub-carriers with $f_{i}$ frequencies. The high range of PAPR is minimized by the electrical amplifier gain [30-32] and is defined as

$$
\frac{P_{\text {out }}}{P_{\text {in }}}=10^{b / 10}
$$

In the presence of PAPR, the NL, LD, and noise power spectral density (PSD) function $[33,34]$ is induced and calculated as

$$
P S D_{n}=\sqrt{ } P_{\text {noise }} \cdot f_{S}
$$

Here, $P_{\text {noise }}$ is noise power, and $f_{s}$ is the frequency grid spacing, which is defined as

$$
f_{s}=\frac{R_{s}}{\psi_{s}}
$$

where $\psi_{s}$ is the channel spacing, and $R_{s}$ is the noise ratio due to channel spacing. The pump laser is installed for transmitting RF signals over OFTL, which induces parameterized optical signals. The optical signals are mathematically estimated as

$$
\left(G_{p}(\iota) / G_{2}(\iota)\right)=\left[\sqrt{\frac{1-Z}{Z e^{i \omega}}}\right] \times \sqrt{P}
$$

where $P$ is the average output power, $\mathrm{Z}$ is used for power splitting, and $\omega$ is the phase difference among the azimuth and explicit rays of light. From Equations (1)-(7), the cosine of the RF signal $S(t)$ is calculated as

$$
S(t)=V_{R F} \cos (2 \pi f)
$$

where $V_{R F}$ is the driving voltage. The intensity modulation (IM) in terms of the optical field is written as

$$
E_{1}=\frac{E_{0}}{2}\left[e^{j \pi\left(\frac{V_{D C}+S(t)}{V_{\pi}}\right)}+e^{-j \pi\left(\frac{V_{D C}+S(t)}{V_{\pi}}\right)}\right]
$$

where $V_{D C}$ is the DC bias voltage, and $V_{\pi}$ explains the IM half wave voltage. It is assumed that $\xi=\pi V_{R F} / V_{\pi}$ and $\omega=\pi V_{D C} / V_{\pi}$, which explain the modulation index and the initial phase caused by $V_{D C}$ of the IM, respectively. From Equation (9), $E_{1}$ can be extended as

$$
\begin{array}{r}
E_{1}(t)=E_{0} \exp \left(j 2 \pi f_{c} t\right) . \\
\left\{\begin{array}{l}
\cos \omega\left[J_{0}(\xi)+2 \Sigma_{i=1}^{\infty}(-1)^{i} J_{2 i}(\xi) \cos \left(4 i \pi f_{s} t\right)\right] \\
+\sin \omega\left[2 \Sigma_{i=1}^{\infty}(-1)^{i} J_{2 i-1}(\xi) \cos (2 i-1) 2 \pi f_{s} t\right]
\end{array}\right.
\end{array}
$$

Here, $J_{i}$ is the $i^{t h}$ order of the Bessel function. The transfer function of the transmitted signal is measured as

$$
H(f)= \begin{cases}\alpha & \left(|f|<f_{1}\right) \\ \beta & \left(f_{1} \leq|f|<f_{2}\right) \\ 0 & f_{2}<|f|\end{cases}
$$

where $\beta$ is written as 


$$
\beta=\sqrt{ } 0.5 \alpha^{2} .1+\cos \left(\left(|f|-f_{1} / r_{p} \cdot \triangle f\right) . \pi\right)
$$

Here, $\alpha$ denotes insertion loss, $r_{p}$ is the roll of factor, and $f_{1}$ and $f_{2}$ are calculated as

$$
\begin{aligned}
& f_{1}=1-r_{P} f_{\mathcal{c}}\left(0 \leq r_{p} \leq 1\right) \\
& f_{2}=1+r_{P} f_{c}\left(0 \leq r_{p} \leq 1\right)
\end{aligned}
$$

The system response is determined by the LDs. The attained signals are calculated as

$$
\begin{gathered}
X_{r}\left(t_{n}\right)=\left[X_{r}\left(t_{n}\right), X_{r}\left(t_{n}-\right.\right. \\
\left.\left.\frac{T_{s}}{Z}, \ldots X_{r}\left(t_{n}-N-1\right)\right) \frac{T_{s}}{Z}\right]
\end{gathered}
$$

where $N$ is the fast Fourier transform (FFT) size, the oversampling factor is denoted by $Z$, $T_{S}$ represents the duration of a single symbol, and $t_{n}$ is the receive timing.

The NLs and LDs in the propagation of the light wave in the fiber are measured as follows:

$$
\begin{aligned}
& \left.i \partial A / \partial z-\beta_{2}\left(\partial^{2} A\right) /\left(\partial t^{2}\right)-i \beta_{3} \partial^{3} A\right) /\left(\partial t^{3}\right)+\gamma|A|^{2} A \\
& =-i \alpha / 2 A
\end{aligned}
$$

Here $A$ represents the complex terms of the electromagnetic field, $t$ represents time, and $z$ denotes the distance of the fiber. For group velocity dispersion (GVD), $\beta_{2}$ is used and is also known as linear dispersion; $\beta_{3}$ is the non-linear dispersion parameter, attenuation is represented by $\alpha$, and $\gamma$ is used as a non-linear coefficient. The relation among the non-linear refractive index $n_{2}$, the carrier wavelength $\lambda_{0}$, and $\gamma$ is given by

$$
\gamma=\left(2 \pi n_{2}\right) / \lambda_{0}
$$

The parameters that affect the amount of NLs and LDs are the cross-section area of SMF, the amount of light intensity propagating through the fiber, the number of channels in the WDM system, and the data rate. These factors generate an-harmonic motions of photons inside the SMF [27], where the behavior of induced polarization $\Omega_{P}$ is no longer linear, and is given as

$$
\Omega_{P}=\varepsilon_{0} \kappa^{\prime} E+\varepsilon_{0} \kappa^{\prime \prime} E^{2}+\varepsilon_{0} \kappa^{\prime \prime \prime} E^{3} .
$$

Here, $\varepsilon_{0}$ describes the free space permittivity, $E$ is the electrical field intensity, and $\kappa^{\prime}, \kappa^{\prime \prime}$, and $\kappa^{\prime \prime \prime}$ determine the first-, second-, and third-order susceptibility, respectively. In order to calculate the frequency domain, the transfer function weight is measured as

$$
F(g)=\exp \left(\frac{-j \vartheta l D f^{2} \pi}{\left(f_{1}-f\right)^{2}}\right)
$$

Here, $\vartheta$ is the speed of light, $l$ is the transmission distance, $D$ is the dispersion coefficient of the optical fiber, $f$ is the frequency of the base-band signals, and $f_{1}$ is the center frequency of the optical signal. In Equation (19), the dispersion slope is ignored due to its lower impact. The LDs are mainly caused by the group velocity dispersion in the fiber. The shift of the transfer function $T(f)$ is defined as

$$
T(f)=\frac{\vartheta l D f}{\left(f_{1}-f\right)^{2}}
$$


Because a high amount of LDs are generated in a long haul transmission, from the $N$ point of the IFFT, the first and last $N_{e}$ samples are eliminated as depicted in Figure 3 . The overlapped samples that are needed can be obtained as

$$
N_{e}=\frac{\vartheta l D f_{m} F_{s}}{f_{\vartheta}^{2}}
$$

Here, $f_{m}$ represents the spectrum edge of the received signal. Regarding the compensate phase noise, the equalizer coefficient using the received signal can be calculated as

$$
\left(t_{n}\right)=\left[r\left(t_{n}\right), r\left(t_{n}-\frac{T_{s}}{A}\right), \ldots r\left(t_{n}-(M-1) \frac{T_{s}}{A}\right)\right]^{T}
$$

where $M$ is the tap size of TDE, $A$ is the overlapping factor, $T_{s}$ is the symbol duration, $n$ is the discrete time of the baud rate, and $t_{n}$ is the receiving time. The equalizer coefficient inside the TDE is explained as

$$
=a\left(t_{n}-T_{s}\right)+\alpha U_{n-1}\left(1-\left|U_{n-1}\right|^{2}\right)\left(t_{n}-T_{s}\right)
$$

where al pha is the step size, and $U_{n}$ is the measured transmitted signal, which is clarified as

$$
U_{n}=\sum_{n=1}^{N} a_{n}\left(t_{n}\right) \gamma\left(t_{n}-(n-1) \frac{T_{s}}{A}\right)
$$

In order to test the efficiency of the outcomes of the proposed work related to NLs, LDs, and phase noise, the BER anaylzer is employed at the receiver side. The bit rate is mathematically defined as

$$
\mathrm{BER}=\frac{1}{2 \operatorname{erf} \sqrt{\frac{\mathrm{OSNR}}{2}}}
$$

The erf denotes error function. The optical signal-to-noise ratio (OSNR) is described as

$$
O S N R=E_{S N R} \frac{\varphi}{2 B_{r} \cdot m_{\text {sys }}}
$$

where $B_{r}$ defines the reference bandwidth, $E_{S N R}$ is the electrical SNR, $\varphi$ is the total transmission symbol rate measured in Gbps, and the last term of Equation (26) $m_{s y s}$ is the system margin.

\section{Results and Discussion}

Section 3 shows that NLs, LDs, and phase noise interrupt the continuity of the WDMRoF system. The impact of these impairments are studied based on simulation analysis in this section. Furthermore, the theoretical mechanism is linked with the simulation model. Equations (1)-(15) indicate the transmitted signal behavior, Equations (16)-(18) summarize the generation and impact of the LDs, NLs, and phase noise, Equations (19)-(24) demonstrate the proposed solution of NLs, LDs, and phase noise, and Equations (25) and (26) are used for evaluating the execution of the projected model.

Hence, the discussed theoretical model simulation analysis is performed as mentioned in Figures 4-10, estimating the data transmission ability in spite of the NLs, LDs, and phase noise. For this purpose, the dominant parameters include channel spacing, SMF transmission range, data rate capacity, input power, received power, and $\mathrm{mmW} R \mathrm{RF}$ bands. Figure 4 shows the relation between the data rate per user and the BER, and cases of $57 \mathrm{GHz}, 59 \mathrm{GHz}$, and $61 \mathrm{GHz}$ total bandwidth with and without NLs and phase noise are compared. The results in Figure 4 show that NLs and phase noise badly distort the operation of a conventional WDM-RoF transmission. Moreover, from the results, it is 
shown that the order of NLs and phase noise also depends on the data rate. For data rates below $50 \mathrm{Gbps}$, the proposed RoF model gives a BER of less than $10^{-3}$ using NLand phase noise-addressing mechanisms. On the other hand, BER values higher than the acceptable range are computed without using the proposed DSP receiver, as mentioned in Figure 4. The simulation analysis of the WDM-RoF for 8, 16, and 32 channels (for a $10 \mathrm{~km}$ transmission range) based on the received power in $\mathrm{dBm}$ and the BER are presented in Figure 5, comparing the performance of the cases with and without compensated NLs and phase noise. A range from $-40 \mathrm{dBm}$ to $-20 \mathrm{dBm}$ of received power is achieved, estimating that, up to $-34 \mathrm{dBm}$, the attained BER is above the limit. With a greater number of channels, the range of BER is also increased, as shown in Figure 5. About a two-digit difference is measured between the 32 and 16 channels transmission system. Furthermore, it is clarified from the results in Figure 5 that the proposed WDM-RoF link with managed NLs and phase noise produces an efficient BER than without managed NLs and phase noise. Channel spacing between the propagating data plays a key role in the performance of the RoF system. Varying the space among channels makes a huge difference in the gain BER, as depicted in Figure 6, containing information related to the channels and the BER. The model is tested based on $12.5 \mathrm{GHz}, 25 \mathrm{GHz}$, and $50 \mathrm{GHz}$ channel spacings and conclude that the the BER increases with decreasing channel spacing. Secondly, it is specified from Figure 6 that not addressing NLs and phase noise gives a BER above the limited range.

Figure 7 explains the outcomes of 4,16,32, and 64 QAM-OFDM formats in terms of input power and BER. Between $-20 \mathrm{dBm}$ and $0 \mathrm{dBm}$ of input power is launched in the proposed model, showing that the BER decreases with more power. Similarly, the performance of the proposed WDM-RoFL was investigated based on several phase noises, i.e., 0, 2.5, 5, and $8 \mathrm{deg}$, as defined in Figure 8. The presented analysis considers a large bandwidth and a large number of WDM channels to ensure that the proposed system model covers the maximum limit for key performance indicators (KPIs) for future communication systems. A normalized optical signal-to-noise ratio (OSNR) was used here to ensure that the system performance is limited due to the Gaussian noise, and not the non-nonlinearities. The trend of the BER versus the OSNR shows that the proposed receiver effectively compensates the NLs and LDs, and hence can be used to implement RoF transport with high reliability.

The model employing a BER analyzer and an optical spectrum analyzer was investigated and is shown in Figures $9 a, c$ and 10a,d, respectively. Figure 9a shows the performance of the WDM-RoF model at a $20 \mathrm{~km}$ transmission range and at $61 \mathrm{GHz}$ RF waves, when there is no technique addressed for controlling NLs, LDs, and phase noise. Figure $9 \mathrm{~b}$ presents the model without NLs, LDs, and phase noise compensated at $20 \mathrm{~km}$ and $59 \mathrm{GHz}$ RF waves. The BER results of the WDM-RoF model where NLs, LDs, and phase noise are reduced are depicted in figure for $20 \mathrm{~km}$ and $61 \mathrm{GHz}$. Figure 10a shows the input transmitted signals, and Figure $10 \mathrm{~b}, \mathrm{c}$ show those without NL-, LD-, and phase-noise-managed signals at $10 \mathrm{~km}$ and $20 \mathrm{~km}$ of path cover with RF $59 \mathrm{GHz}$, respectively. The NL-, LD-, and phase noise-compensated output signals at a path cover of $20 \mathrm{~km}$ are presented in Figure 10d. In addition, the performance of the proposed setup is analyzed for different lengths, channel spacings, and data rates, and compensation procedures of NLs, LDs, and phase noise are depicted in Table 2. Similarly, Table 3 clarifies the outcomes of the presented model and models from other publications in terms of channel spacing, BER, the length of SMF, and the methodology. 


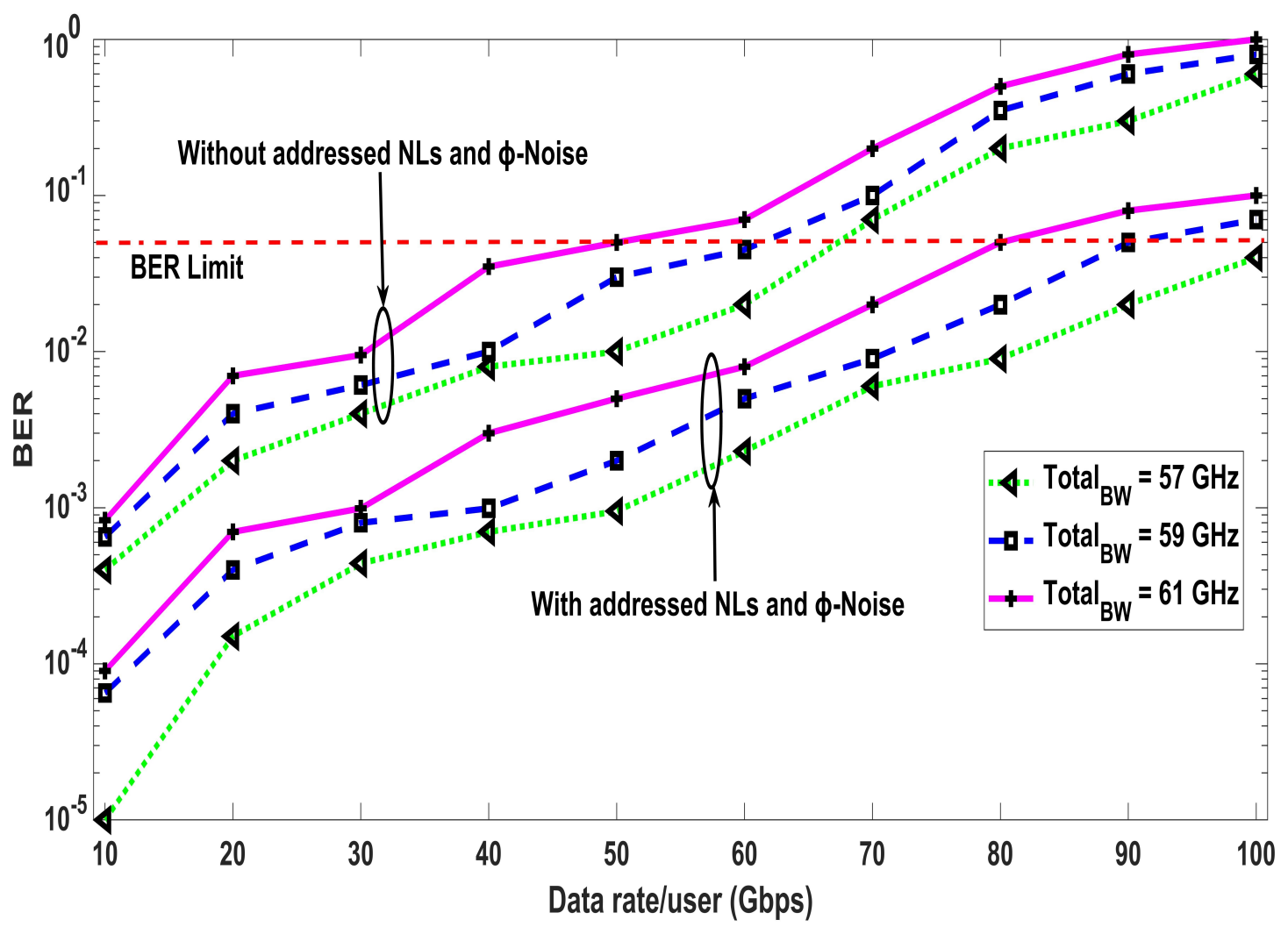

Figure 4. Analysis of different bandwidth capacities in terms of BER and data rate.

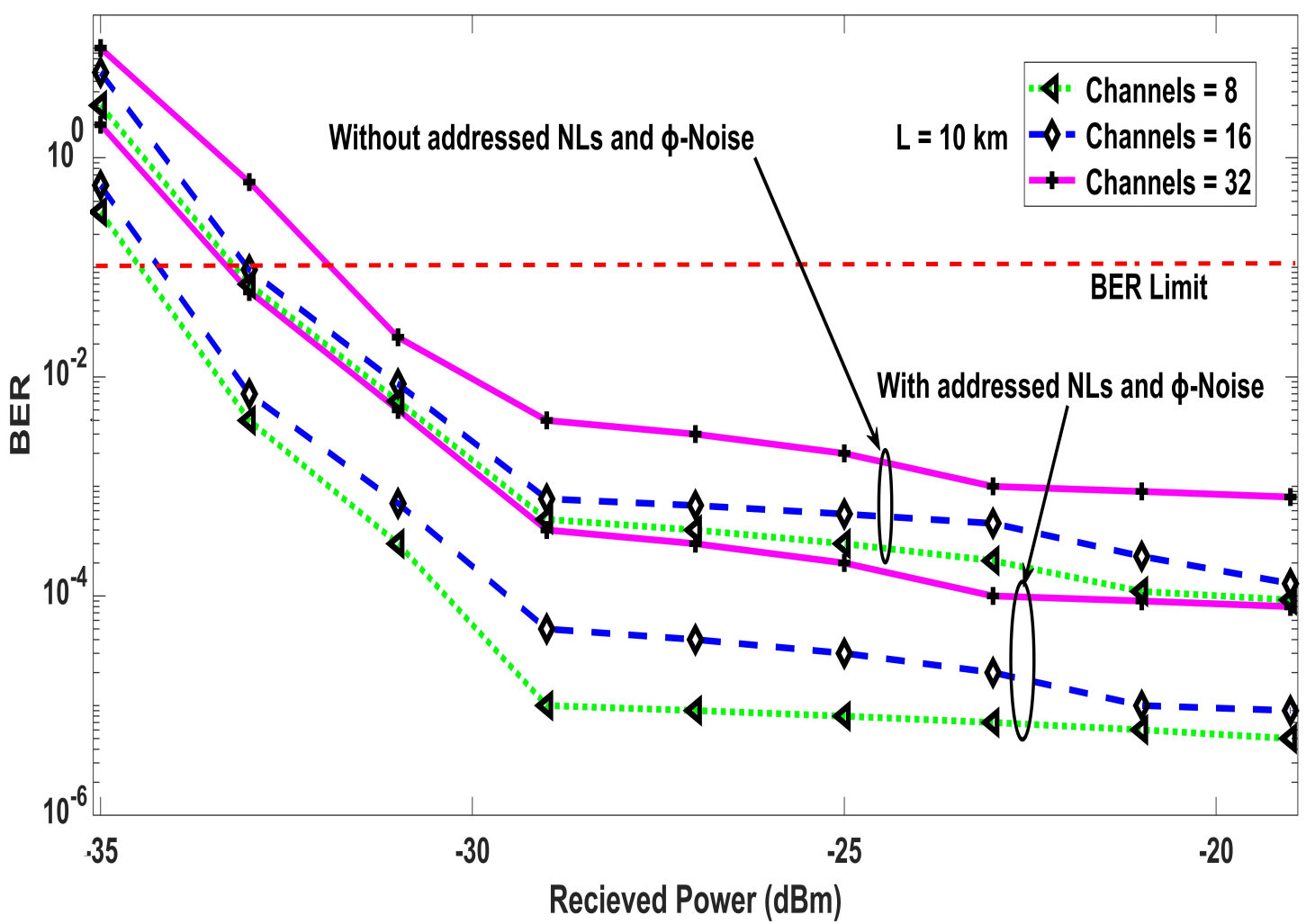

Figure 5. Received power vs. BER at 8,16 , and 32 channels. 


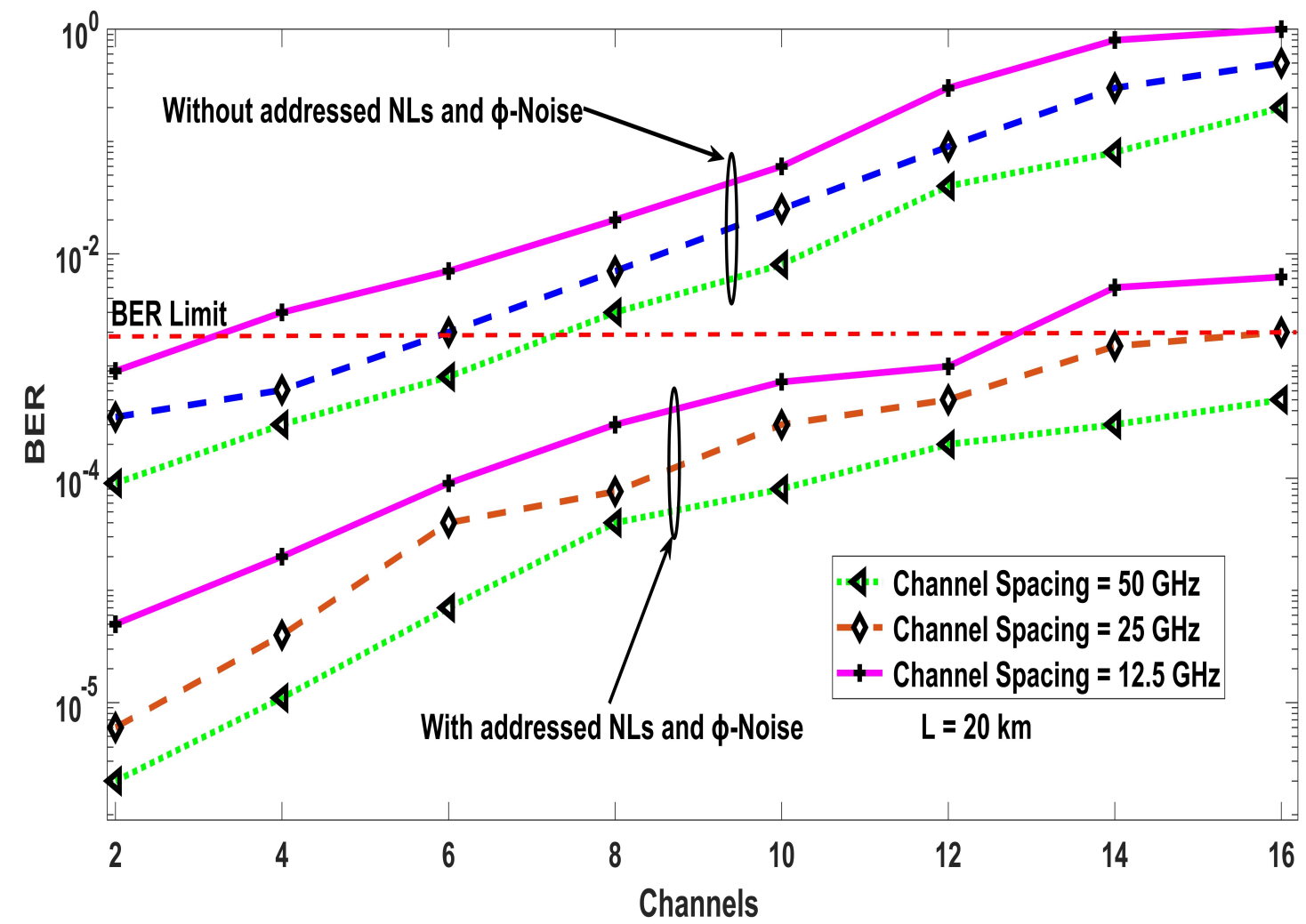

Figure 6. Comparison of various types of channel spacing and fiber length in terms of BER and the quantity of channels.

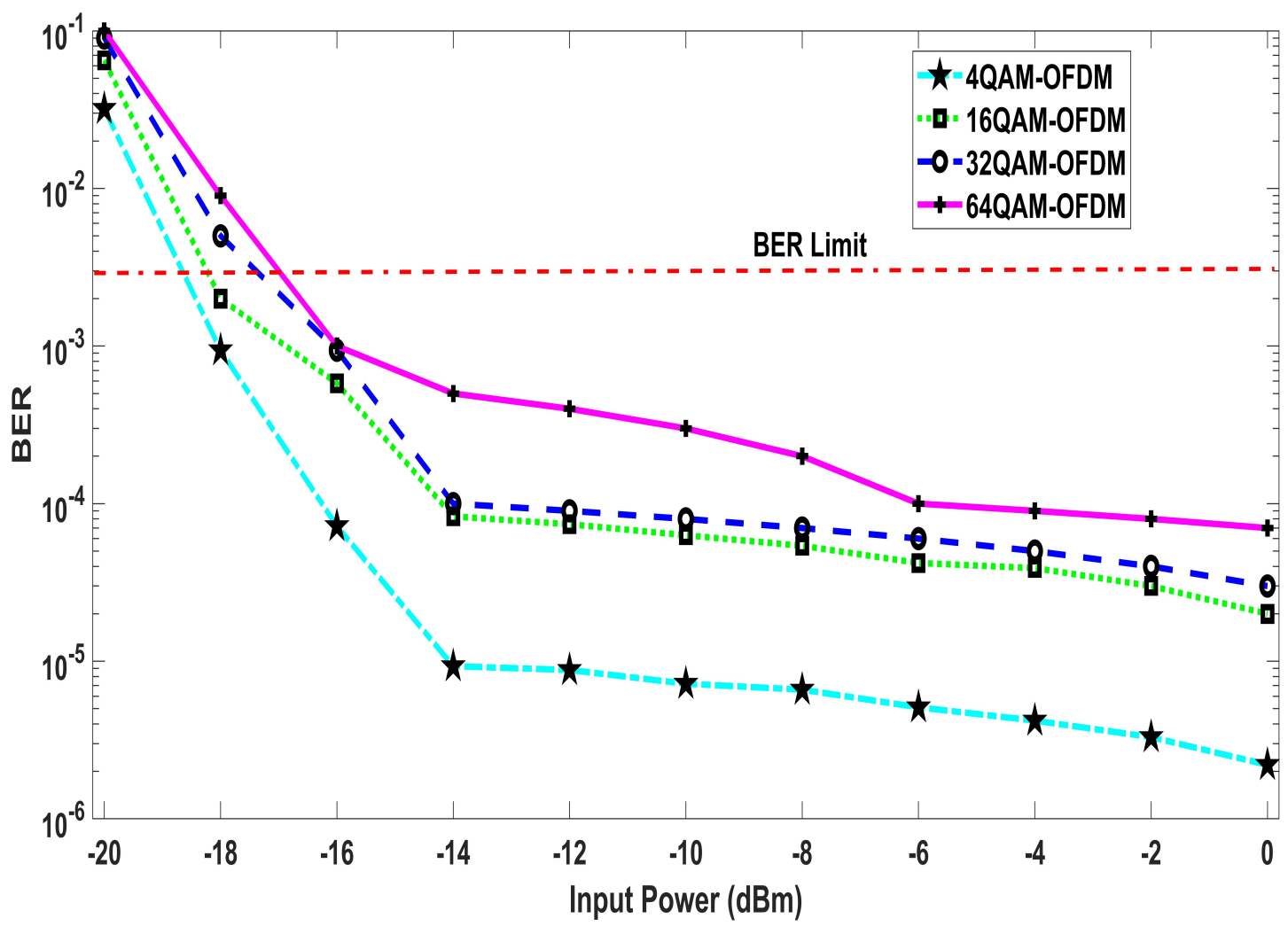

Figure 7. Analysis of different QAM-OFDM formats in terms of BER and input power. 


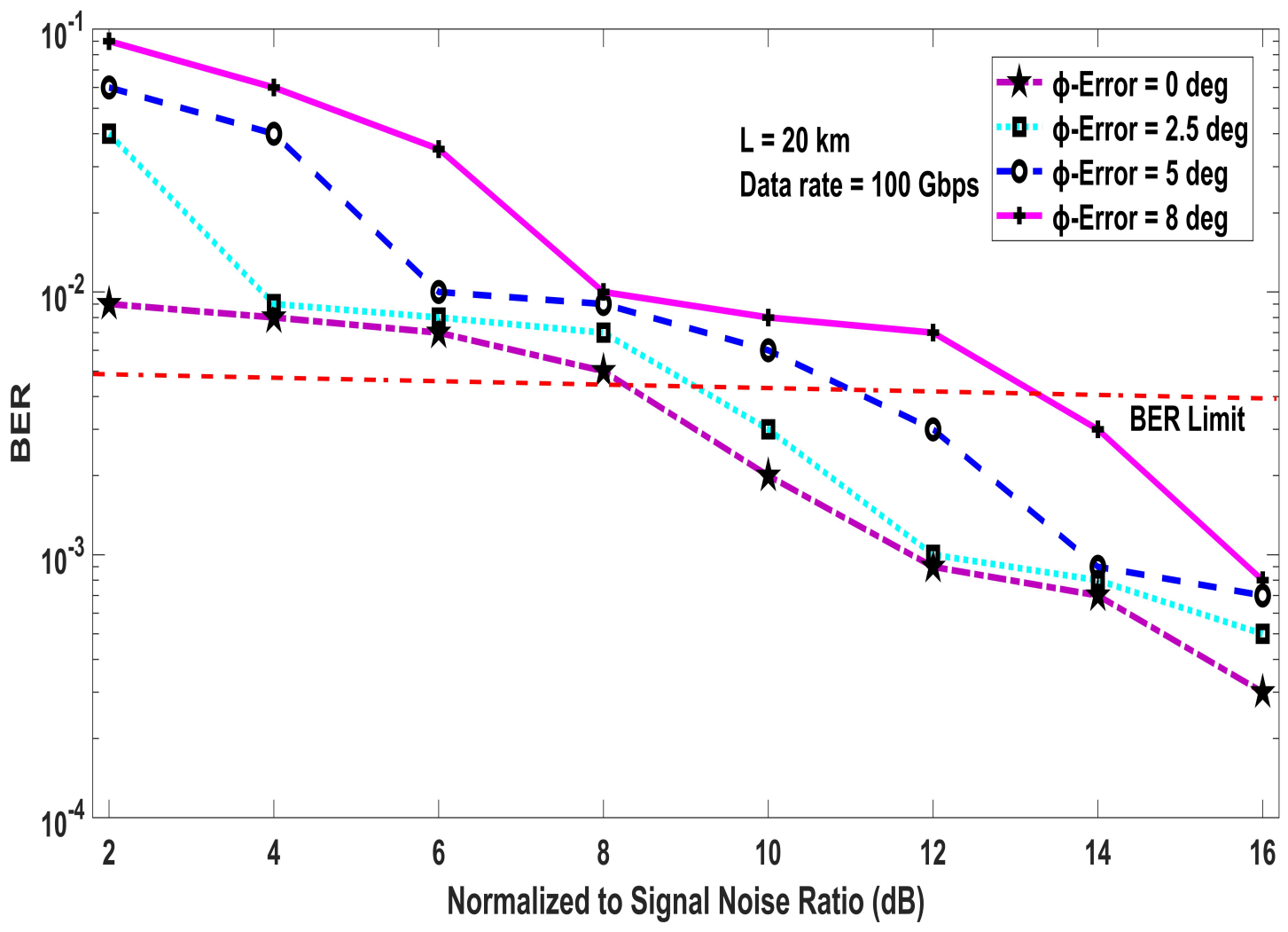

Figure 8. Outcomes of $0,2.5,5$, and $8 \mathrm{deg}$ phase noise based on the normalized signal-to-noise ratio and the BER.

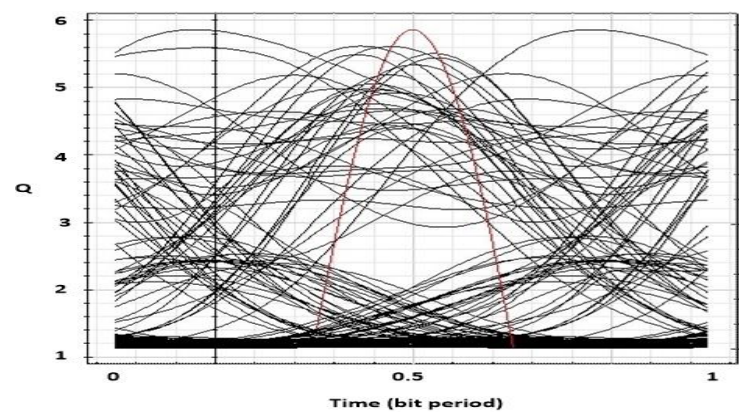

(a)

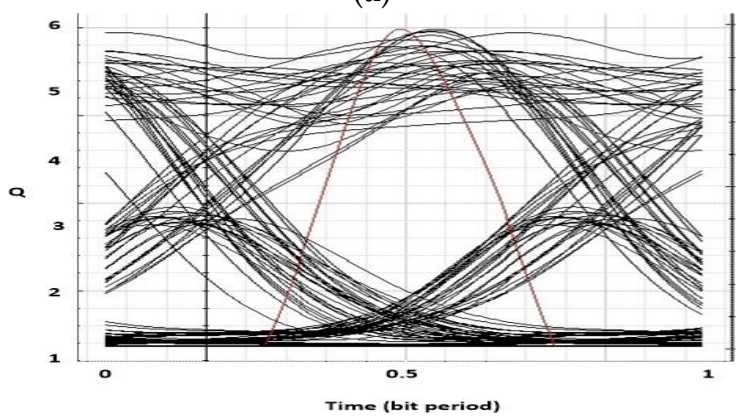

(c)

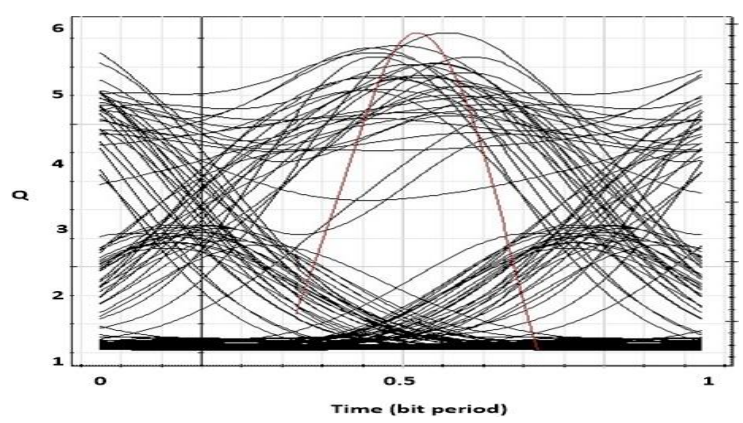

(b)

Figure 9. BER eye-diagrams. (a) Distorted eye diagram when no technique is applied for compensating NLs, LDs, and phase noise at $61 \mathrm{GHz}$ RF waves and $20 \mathrm{~km}$ of transmission path cover. (b) Distorted eye diagram when no technique is applied for compensating NLs, LDs, and phase noise at $57 \mathrm{GHz}$ RF waves and $10 \mathrm{~km}$ of transmission path cover. (c) Eye diagram of the NL-, LD-, and phase-noise-compensated RoF model at $61 \mathrm{GHz}$ RF waves and a $20 \mathrm{~km}$ fiber range. 


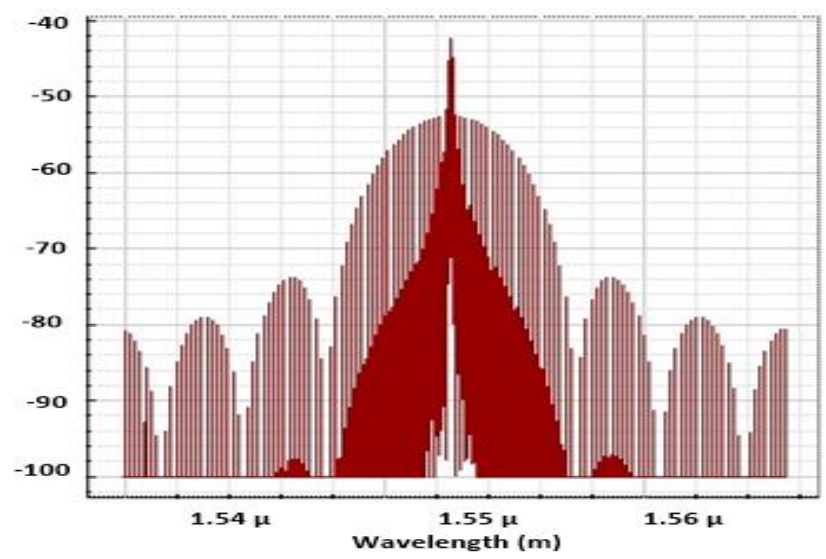

(a)

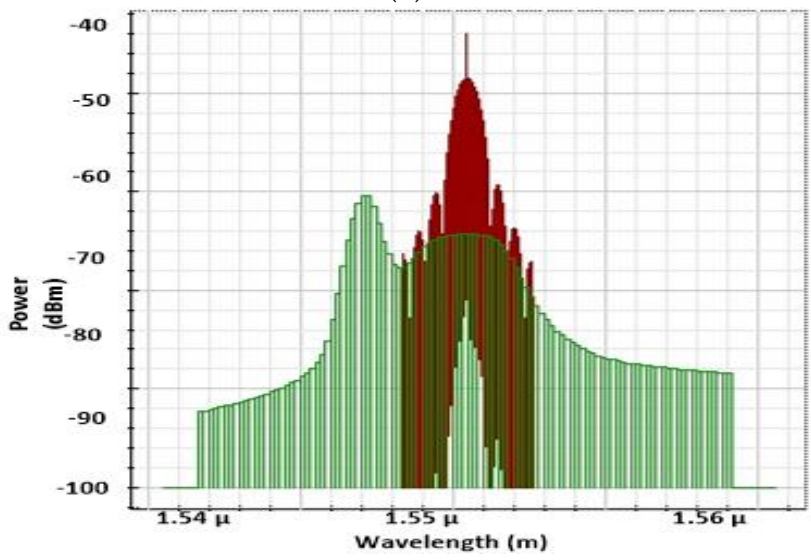

(c)

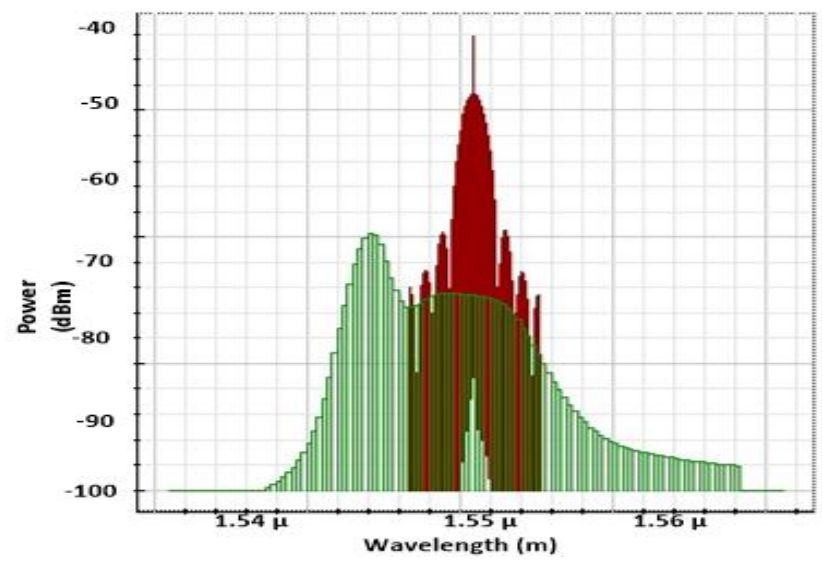

(b)

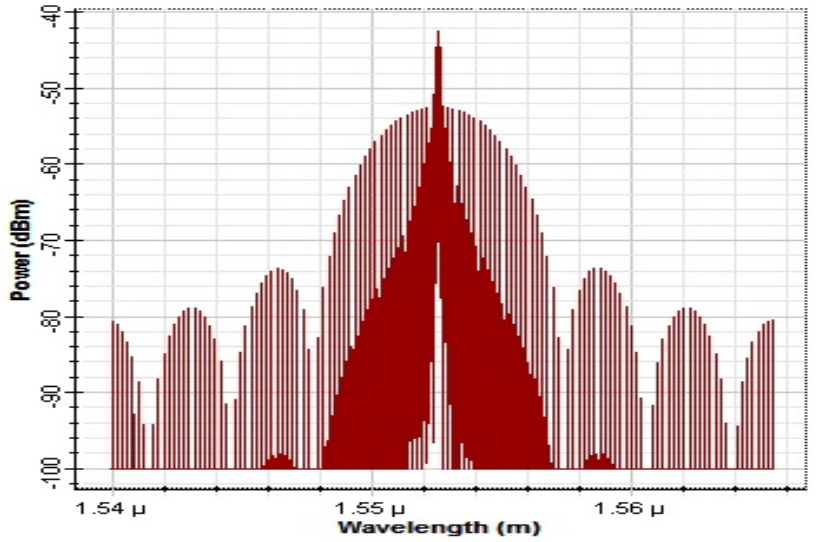

(d)

Figure 10. Optical spectrum analyzer. (a) Input transmitted signals. (b) Without managing of NLs, LDs, and phase noise at a $10 \mathrm{~km}$ length. (c) Without managing NLs, LDs, and phase noise at a $20 \mathrm{~km}$ length. (d) NL-, LD-, and phase-noisecompensated outcomes for a $20 \mathrm{~km}$ path cover.

Table 2. Comparison of NLs, LDs, and phase noise at different conditions.

\begin{tabular}{cccc}
\hline Description & LDs Compensation & Phase Noise Compensation & NLs Compensation \\
\hline BER at 10 km SMF & $2.1 \times 10^{-4}$ & $4.2 \times 10^{-5}$ & $3.5 \times 10^{-6}$ \\
BER at 20 km SMF & $6.2 \times 10^{-3}$ & $2.0 \times 10^{-4}$ & $1.3 \times 10^{-5}$ \\
BER at 100 Gbps & $8.1 \times 10^{-4}$ & $1.5 \times 10^{-5}$ & $3.6 \times 10^{-6}$ \\
BER at 12.5 GHz Channel spacing & $7.4 \times 10^{-4}$ & $5.1 \times 10^{-4}$ & $9 \times 10^{-5}$ \\
BER at 25 GHz Channel spacing & $2.1 \times 10^{-4}$ & $9.1 \times 10^{-5}$ & $2.1 \times 10^{-5}$ \\
BER at 50 GHz Channel spacing & $1.7 \times 10^{-5}$ & $4.31 \times 10^{-6}$ & $1.1^{-6}$ \\
\hline
\end{tabular}

Table 3. Performance analysis of the proposed model in terms of current approaches.

\begin{tabular}{cccc}
\hline Description & {$[35]$} & {$[36]$} & Presented Model \\
\hline SimulationTool & Optisystem & Optisystem & Optisystem \\
SMF & $15 \mathrm{~km}$ & $10 \mathrm{~km}$ & $20 \mathrm{~km}$ \\
BER & Below $10^{-4}$ & Below $10^{-4}$ & Below $10^{-4}$ \\
Channel spacing & $12.5 \mathrm{GHz}$ & $25 \mathrm{GHz}$ & $12.5,25$ and $50 \mathrm{GHz}$ \\
NLs & Nil & yes & Yes \\
LDs & $\mathrm{CD}$ & Nil & CD, PMD \\
\hline
\end{tabular}




\section{Conclusions}

The WDM-RoF model is considered a promising solution in the current era for supporting a large number of users for high-data-rate-demanding multimedia-based services. Therefore, in this paper, a novel WDM-RoF model is projected based on OFDM modulated data transmission. NLs, LDs, and phase noise are studied and minimized in the presented model. The model is analyzed with an RF and optical domain infrastructure, and simulations are carried out using a realistic set of values. A mathematical model is investigated using the proposed analytical model to explore the originality of the transmitted signals, the discontinuity of pulses due to the optical domain, and electrical-domain-related issues, i.e. NLs, LDs, and phase noise. The presented model is investigated in a 1-20 km of transmission range, at $57-61 \mathrm{GHz}$ RF bandwidths, at an input power between -20 and $0 \mathrm{dBm}$, at a received power from $-40 \mathrm{dBm}$ to $-18 \mathrm{dBm}$, and with a $0-20$ normalized signal-to-noise ratioThe complexity of the RoF link is reduced with enhanced quality by configuring the OFDE and TDE blocks at the 16/32/64 QAM-OFDM receiver. The OFDE and TDE configuration aims to handle NLs, LDs, and phase noise in SMF fibers installed as a backbone for RoF transmission. The simulation analysis shows that an RoF-transmission-based OFDE configuration is robust against NLs, LDs, and phase noise. It is found from the results that OFDE- and TDE-based RoF models are applicable for short- and long-range transmission. It is also concluded that the proposed solution provides a superior performance, with suppressed NLs, LDs, and phase noise as compared to conventional RoF systems.

Author Contributions: Conceptualization, F.A. (Farman Ali), M.K.A.K., M.I. and F.M.; methodology, F.A. (Farman Ali), S.R., S.K., A.G. and F.A. (Faisal Althobiani); software, F.A. (Farman Ali), M.K.A.K. and A.A.; validation, F.A. (Faisal Althobiani) and F.M.; formal analysis, F.A. (Farman Ali), F.A. (Faisal Althobiani) and S.R.; investigation, S.K., M.K.A.K., M.I., A.G. and F.M.; data analysis, F.A. (Faisal Althobiani) and G.P.; writing —original draft preparation, F.A. (Farman Ali); writing-review and editing, F.M., S.R., A.A., S.K. and F.M.; visualization, S.R.; supervision, F.A. (Farman Ali) and F.M.; project administration, S.R., M.K.A.K., F.A. (Faisal Althobiani), F.M., G.P. and M.I.; funding acquisition, M.K.A.K. All authors have read and agreed to the published version of the manuscript.

Funding: The authors would like to express their gratitude to the Ministry of Education and the Deanship of Scientific Research, Najran University. Kingdom of Saudi Arabia, for their financial and technical support under code number NU/ESCI/17/065.

Data Availability Statement: Data is contained within the article.

Acknowledgments: The authors would like to express their gratitude to the Ministry of Education and the Deanship of Scientific Research, Najran University. Kingdom of Saudi Arabia, for their financial and technical support under code number NU/ESCI/17/065.

Conflicts of Interest: The authors declare no conflict of interest.

\section{References}

1. Tian, F.; Zhang, P.; Yan, Z. A survey on C-RAN security. IEEE Access 2017, 55, 13372-13386. [CrossRef]

2. Sharma, S.R.; Rana, S. Comprehensive study of radio over fiber with different modulation techniques-A Review. Int. J. Comput. Appl. 2017, 170, 22-25. [CrossRef]

3. Ilgaz, M.A.; Baliz, K.V.; Batagelj, B. A Flexible Approach to Combating Chromatic Dispersion in a Centralized 5G Network. Opto-Electron. Rev. 2020, 28, 35-42.

4. Lim, C.; Lee, K.; Nirmalathas, A.; Novak, D.; Waterhouse, R. Impact of chromatic dispersion on 60 GHz radio-over-fiber transmission. In Proceedings of the LEOS 2008-21st Annual Meeting of the IEEE Lasers and Electro-Optics Society, Acapulco, Mexico, 9-13 November 2008; pp. 89-90. [CrossRef]

5. Abdulrazzaq, A.A.; Abid, A.J.; Ali, A.H. QoS performances evaluation for mobile WIMAX networks based on OPNET. Int. J. Appl. Eng. Res. 2018, 13, 6545-6550.

6. Xu, T.; Shevchenko, N.A.; Lavery, D.; Semrau, D.; Liga, G.; Alvarado, A.; Killey, R.I.; Bayvel, P. Modulation format dependence of digital nonlinearity compensation performance in optical fibre communication systems. Opt. Express 2017, 25, 3311-3326. [CrossRef] [PubMed] 
7. El-Nahal, F.I. A WDM-PON with DPSK modulated downstream and OOK modulated upstream signals based on symmetric $10 \mathrm{Gbit} / \mathrm{s}$ wavelength reused bidirectional reflective SOA. Opt. Lett. 2017, 13, 67-69. [CrossRef]

8. Cartledge, J.C.; Guiomar, F.P.; Kschischang, F.R.; Liga, G.; Yankov, M.P. Digital signal processing for fiber nonlinearities. Opt. Express 2017, 25, 1916-1936. [CrossRef]

9. Bakhshali, A.; Chan, W.Y.; Cartledge, J.C.; OSullivan, M.C.; Laperle Borowiec, A.; Roberts, K. Frequency-domain Volterra-based equalization structures for efficient mitigation of intrachannel Kerr nonlinearities. J. Light. Technol. 2016, 34, 1770-1777. [CrossRef]

10. Liu, X.; Chraplyvy, A.; Winzer, P.; Tkach, R.; Chandrasekhar, S. Phase-conjugated twin waves for communication beyond the Kerr nonlinearity limit. Nat. Photonics 2013, 7,560. [CrossRef]

11. Dong, Y.; Rawachy, E.; Giddings, A.; Jin, R.P.; Nesset, D.W.; Tang, J.M. Multiple channel interference cancellation of digital filter multiple access PONs. Int. J. Light. Technol. 2017, 35, 34-44. [CrossRef]

12. Ke, J.H.; Gao, Y.; Cartledge, J.C.; Hasegawa, T.; Yamamoto, Y.; Hirano, M. 400 Gbit/s optimal fiber design for large capacity long haul coherent transmission. Opt. Express 2017, 25, 706-712.

13. Habib, U.; Aighobahi, A.E.; Quinlan, T.; Walker, S.D.; Gomes, N.J. Demonstration of radio-over-fiber-supported 60 GHz MIMO using separate antenna-pair processing. In Proceedings of the 2017 International Topical Meeting on Microwave Photonics (MWP), Beijing, China, 23-26 October 2017; pp. 1-4.

14. Wang, B.; Peng, L.; Ho, P. Energy-efficient radio-over-fiber system for next-generation cloud radio access networks. J. Wireless Com. Netw. 2019, 118. [CrossRef]

15. Ali, F.; Khan, Y.; Ali, A. Impact of Nonlinear Impairments on Power Budget and Transmission Power Penalties in High Capacity Long Haul Optical Networks. J. Wirel. Pers. Commun. 2019, 106, 1001-1013.

16. Ali, A.H.; Farhood, A.D. Design and performance analysis of the WDM schemes for radio over fiber system with different fiber propagation losses. Fibers 2019, 7, 19. [CrossRef]

17. Li, G.; Lin, Z.; Huang, X.; Li, J. A radio over fiber system with simultaneous wireless multi-mode operation based on a multi-wavelength optical comb and pulse-shaped 4QAM-OFDM. Electronics 2019, 8, 1064. [CrossRef]

18. Li, J.L.; Zhao, F.; Yu, J. D-band millimeter wave generation and transmission though radio-over-fiber system. IEEE Photonics J. 2020, 12, 5500708. [CrossRef]

19. Ali, F.; Ahmad, S.; Muhammad, F.; Abbas, Z.H.; Habib, U.; Kim, S. Adaptive equalization for dispersion mitigation in multichannel optical communication networks. Electronics 2019, 8, 1364. [CrossRef]

20. Sharma, V.; Sergeyev, S.; Kaur, J. Adaptive $2 \times 2$ MIMO employed wavelet-OFDM-radio over fibre transmission. IEEE Access 2020, 8, 23336-23345. [CrossRef]

21. Kim, J.; Lee, H.; Park, S.; Lee, I. Minimum Rate Maximization for Wireless Powered Cloud Radio Access Networks. IEEE Trans. Veh. Technol. 2019, 68, 1045-1049. [CrossRef]

22. Muhammad, F.; Ali, F.; Habib, U.; Usman, M.; Khan, I.; Kim, S. Time domain equalization and digital back-propagation method-based receiver for fiber optic communication systems. Int. J. Opt. 2020, 2020, 3146374. [CrossRef]

23. Qamar, F.; Islam, M.K.; Ali, S.Z.; Ali, M. Secure duobinary signal transmission in optical communication networks for high performance \& reliability. IEEE Access 2018, 5, 17795-17802.

24. Zhang, H.; Batshon, H.G.; Davidson, C.R.; Foursa, D.G.; Pilipetskii, A. Multi dimensional coded modulation in long-haul fiber optic transmission. J. Light. Technol. 2015, 33, 2876-2883. [CrossRef]

25. Ali, F.; Khan, Y.; Muhammad, F.; Habib, U.; Abbas, Z.H.; Khan, M.A.; Ali, A. Extenuation of phase shift influenced nonlinear impairments in fiber optics network. Trans. Emerg. Telecommun. Technol. 2020, 31, e3930. [CrossRef]

26. Benyahya, K.; Simonneau, C.; Ghazisaeidi, A.; Barr, N.; Jian, P.; Morizur, J.F.; Labroille, G.; Bigot, M.; Sillard, P.; Provost, J.G.; et al. Multiterabit transmission over OM2 multimode fiber with wavelength and mode group multiplexing and direct detection. $J$. Light. Technol. 2018, 36, 355-360. [CrossRef]

27. Ali, F.; Khan, Y.; Ali, A.; Ahmad, G. Minimization of nonlinear impairments and its impact on transmission performances of high-capacity long-haul optical networks. J. Opt. Commun. 2018. [CrossRef]

28. Maharana, D.; Rout, R. A 4 channel WDM based hybrid optical Fiber/FSO communication system using DP QPSK modulation for bit rate of 100/112 Gb/s. Int. J. Eng. Res. Technol. 2019, 8, 442-445.

29. Obaid, H.M.; Shahid, H. Achieving high gain using Er-Yb codoped waveguide/fiber optical parametric hybrid amplifier for dense wavelength division multiplexed system. Opt. Eng. 2018, 57, 056108. [CrossRef]

30. Niaz, V.; Qamar, F.; Islam, K.; Shahzad, A.; Shahzadi, R.; Ali, M. Performance analysis and comparison of QPSK and DP-QPSK based optical fiber communication systems. ITEE J. 2018, 7, 34-39.

31. Tipsuwannakul, E.; Li, J.; Karlsson, M.; Andrekson, P.A. Performance comparisons of DP16-QAM and duobinary-shaped DP-QPSK for optical systems with $4.1 \mathrm{Bit} / \mathrm{s} / \mathrm{Hz}$ spectral efficiency. J. Lightwave Technol. 2012, 30, 2307-2314. [CrossRef]

32. El-Naha, F.I. Coherent quadrature phase shift keying optical communication systems. Opt. Lett. 2018, 14, 372-375. [CrossRef]

33. Kahn, J.M.; Miller, D.A.B. Communications expands its space. Nat. Photonics 2017, 11, 5-8. [CrossRef]

34. Ali, F.; Muhammad, F.; Habib, U.; Khan, Y.; Usman, M. Modeling and minimization of FWM effects in DWDM-based long-haul optical communication systems. Photon Netw. Commun. 2020. [CrossRef] 
35. Nguyen, D.-N.; Bohata, J.; Spacil, J.; Komanec, M.; Stevens, N.; Ghassemlooy, Z. Polarization Division Multiplexing-Based Hybrid Microwave Photonic Links for Simultaneous mmW and Sub-6 GHz Wireless Transmissions. IEEE Photonics J. 2020, 12, 1-14. [CrossRef]

36. Irfan, M.; Ali, F.; Muhammad, F.; Alwadie, A.S.; Glowacz, A.; Goldasz, I.; Mielnik, R.; Alkahtani, F.S.; Khan, H. An Optimal Framework for WDM Systems Using Analytical Characterization of Refractive Index-Related Nonlinear Impairments. Electronics 2021, 10, 221. [CrossRef] 